\title{
ADAPTATION OF INSURANCE DISTRIBUTION TO THE NEW CHALLENGES
}

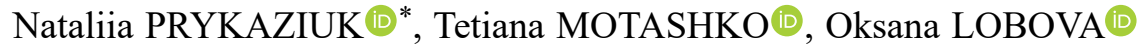 \\ Insurance, Banking and Risk-Management Department, Economic Faculty, \\ Taras Shevchenko National University of Kyiv, Vasylkivska, 90 A, 03022 Kyiv, Ukraine
}

Received 28 February 2021; accepted 01 April 2021

\begin{abstract}
Purpose - new challenges, including those induced by the Covid-19 pandemic and digital power, are exacerbating instability for each entity and increasing the role of insurance, while necessitating the reformatting of existing approaches to insurance distribution. The purpose of the article is to develop a model of adaptation of the insurance distribution system to new challenges by elucidating the distribution channels transformation during the last decade in European countries, establishing causal links, identifying factors that determine current trends in insurance distribution.

Research methodology - the economic and statistical methods of collecting and processing the information, methods of structural and dynamic analysis, analysis and synthesis, empirical methods are usedto achieve the stated goal of the article.

Findings - a model for adapting the insurance distribution to new challenges, including the Covid-19 pandemic and digital power, which is based on the current trends and transformation processes of insurance distribution in European countries, the features of the insurance distribution system, aimed at innovation and the establishment of insurance ecosystemsis developed.

Research limitations - limitations of the study are represented by the gaps in available statistical information for individual countries.

Practical implications - the results of the study, including the proposed model, can help insurance companies achieving the sustainable development goals, taking into account new challenges.

Originality/Value - this study delivers its contribution by demonstrating the trends, drivers and ways to adapt the insurance distribution in the new realities.
\end{abstract}

Keywords: digital power, insurance distribution, adaptation, pandemic, innovation, ecosystem.

JEL Classification: G22.

Conference topic: Business Processes: Development, Digitalization, Social Responsibility.

\section{Introduction}

The insurance services distribution is an important complex of business processes of an insurance company. Insurer's performance depends on its successful result. Under the current operating environment, insurance companies need to develop and improve the insurance services distribution in order to approach the customer and be able not only meeting the needs of the insurance services' consumers, but also meeting their growing demands. Given the competition in the insurance industry, those insurers who will pay due attention to the insurance services distribution will be able remaining competitive. Hence, it is advisabledeveloping a model of adaptation of the insurance services distribution system to the new challenges by clarifying the transformation of distribution channels over the last decade in European countries, establishing cause-and-effect relationships, identifying factors that determine current trends in the distribution of insurance services.

In order to achieve this goal, we consider solving the following tasks:

- define the essence and outline the key subjects of the insurance services distribution;

\footnotetext{
"E-mail: pnvuniv15@ukr.net
}

(C) 2021 Authors. Published by Vilnius Gediminas Technical University. This is an open-access article distributed under the terms of the Creative Commons Attribution (http://creativecommons.org/licenses/by/4.0/) License, which permits unrestricted use, distribution, and reproduction in any medium, provided the original author and source are credited. 
- analyze the participation of each of these subjects in the insurance services distribution over a ten-year period in European countries and Ukraine;

- identify innovations in the insurance services distribution;

- propose a model of adaptation of the insurance services distribution system to the new challenges.

\section{The essence of the insurance services distribution}

The concept of the insurance services distribution is widely used in the scientific publications. However, enough attention is not given to the study of the essence of this concept. For example, Yu. Klapkiv examines the role of mobile applications in the online insurance services distribution. Also, the author defines the essence of the "distribution" concept, considering the latter as the process of moving products and services from producer to end consumer (Klapkiv, 2018). Another work demonstrates the following meaning of the concept: "manifestation of ties and market relations between buyers and suppliers of insurance products". Considerable attention is also paid to the forms of the insurance services distribution. "Distribution of insurance services takes on different forms, among which the main ones are distinguished - direct and indirect channels" (Klapkiv et al., 2018). Pikus and Zakolodyazhnyi (2016) paid attention to innovative channels of insurance products in the field of personal insurance in her research, and Sholoyko (2016) reviewed the European legislation in the field of insurance mediation, where she defined insurance mediation as "an important channel of sale" of insurance services.

Regan and Tennyson (1998) previse that "Insurance distribution span the spectrum from the use of a professional employee sales force, to contracting with independent sales representatives, to direct response methods such as mail and telephone solicitation". Instead, although Clipici and Bolovan (2012) do not pay much attention thestudyofth distribution concept, however, when considering other aspects of distribution, they distinguish between "sales" and "distribution", pointing out: "Bancassurance - main insurance distribution and sale channel".

From our point of view, Tkachenko and Riabokon (2016) opinion, namely "understanding the the insurance product implementation as the processes of developing an insurance product, its market launch, sales and after-sales service", is quite reasonable.

Thus, in many publications, the concept of the insurance services distribution is identified with their sale, retail, that is, the distribution concept is used in a narrow sense. However, in our opinion, distribution is a broader notion in its essence and includes not only the stage of insurance services sales but also other stages.

Hence, it is worthwhile paying attention to defining the examined concept in international documents. Thus, in accordance with Directive (EU) 2016/97 of the European Parliament and of the Council of 20 January 2016 on insurance distribution, theinsurance services distribution means to sell, propose to sell, advise on or prepare in any other way the conclusion of insurance contracts (other actions aimed at preparing an insurance contract) (European Parliament \& Council of the European Union, 2016; European Commission, n.d.).

In addition, Swiss Re's (2014) Digital Distribution in Insurance: A Quiet Revolution publishes the broad meaning of distribution, which states that distribution goes beyond the sale of insurance services and goes beyond the scope of a sales agreement (Swiss Re, 2014).

Thus, the concept of the insurance services distribution, based on the results of the conducted research, may be considered in domestic and international publications in a narrow or wide sense, or not defined at all. In our point of view, its broad understanding is much better at defining the essence of the insurance services distribution, including not only sales but also a range of additional activities.

\section{Modern trends and transformational processes of the insurance services distribution in European countries}

Finding a customer and selling the services are the key activities in the process of the insurance services distribution. The main subjects of this process are shown in Figure 1.

Insurance companies, insurance intermediaries (agents and brokers), as well as ancillary insurance intermediaries (alternative, non-insurance) (companies providing insurance services in addition to offered products and services. Typical examples of ancillary insurance intermediaries are travel agencies or airlines that offer travel insurance) can participate in the distribution of insurance services (Bipar, n.d.). In general, the presence of a wide range of such entities in the insurance market stimulates them improving the quality of services provided due to increased competition in the market. In addition, the diversity of insurance sellers makes it possible for consumers having the broad access to such services and taking into account the preferences of each of them.

It is worth noting that there is a different relationship between these distribution entities in different countries that is caused not only by the specific features of insurance services, but also by the cultural and historical characteristics of the country. At the same time, the structure of the insurance services distribution is constantly changing and improving according to the needs of consumers. 


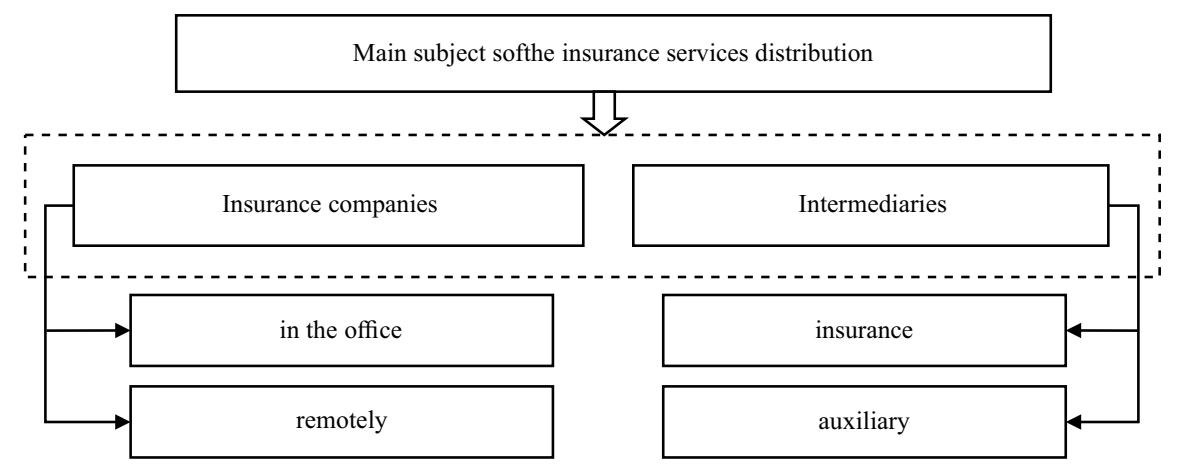

Figure 1. Main subjects of the insurance services distribution (source: developed by the authors)

\subsection{Insurance intermediaries in the insurance services distribution}

Insurance intermediaries, namely agents and brokers, play an important role in the insurance services distribution. Consumers consider them as one of many interactions with the insurer (Bieck \& Cornelius, 2014). Their mission in the market of insurance services, in the process of the insurance services distribution, is as follows:

- comprehensive promotion of insurance protection;

- use and dissemination of innovative marketing;

- increasing the consumer awareness of the importance of insurance;

- promoting the dissemination of information among consumers, enhancing their insurance culture;

- consulting, assistance in selecting an insurance product that meets the insurers needs as close as possible;

- promoting the increased demand for insurance;

- creating competition among insurers;

- informational support of insurance companies;

- assistance in the new insurance products development;

- promoting the competitiveness of insurers;

- assistance in risk sharing of insurance companies;

- assistance in reducing the costs of insurers (Prykaziuk, 2017).

It is important to note that in European countries the share of such sellers of insurance services by non-life insurance types is on average more than $60 \%$, including agents $-41.8 \%$, and brokers $-25.1 \%$ (Table 1) (Insurance Europe, 2020). Such trend is virtually unchanged over the long period of time and will continue being relevant in the future. Although recently they have been competing with innovative channels / platforms.

In this case, insurance agents are most common in the insurance services distribution in such countries as France, Germany, Greece, Italy, Luxembourg, Portugal and Spain. As for brokers, they are the main sellers of insurance services, especially by non-life insurance types, in countries such as Belgium, the Netherlands and the United Kingdom (Bipar, n.d.).

Table 1. Share of insurance agents and brokers in the insurance services distribution in European countries during 2007-2017, \% (source: compiled by the authors using Insurance Europe, 2020)

\begin{tabular}{|c|c|c|c|c|}
\hline \multirow{2}{*}{ Year } & \multicolumn{2}{|c|}{ Agents } & \multicolumn{2}{c|}{ Brokers } \\
\cline { 2 - 5 } & Life & non-Life & 21.2 & 26.0 \\
\hline 2007 & 30.9 & 46.1 & 11.2 & 27.0 \\
\hline 2008 & 34.0 & 46.5 & 10.5 & 26.5 \\
\hline 2009 & 31.1 & 44.9 & 10.4 & 24.6 \\
\hline 2010 & 33.4 & 45.6 & 9.2 & 21.4 \\
\hline 2011 & 29.9 & 45.6 & 13.1 & 24.1 \\
\hline 2012 & 27.5 & 44.2 & 5.1 & 24.3 \\
\hline 2013 & 36.3 & 43.8 & 8.3 & 22.6 \\
\hline 2014 & 34.3 & 46.1 & 8.8 & 21.1 \\
\hline 2015 & 33.2 & 45.8 & 8.8 & 25.1 \\
\hline 2016 & 27.4 & 43.4 & 10.0 & \\
\hline 2017 & 30.2 & 41.8 & & \\
\hline
\end{tabular}


In European countries insurance intermediaries and peculiarities of their activity are featured by considerable diversity. In particular, the differences are in the features of their registration and reporting, the number of functioning (registered) agents and brokers, as well as the categories of such intermediaries. The types of insurance intermediary in the market varies depending on the jurisdiction, reflecting different activities undertaken by intermediaries, as well as the legal and regulatory frameworks applying to the distribution of insurance products (OECD, 2020).

It should be noted that there are different types of insurance agents in the world that proves the necessity of their systematization. In general, given the international experience in the field of the insurance intermediaries functioning, as important sellers of insurance services, it is possible to provide a generalized classification of such entities in the insurance services market (Table 2).

Table 2. Generalized classification of insurance agents as subjects of the insurance services distribution (source: developed by the authors according to Prykaziuk, 2017)

\begin{tabular}{|c|c|c|}
\hline No & Classification feature & Types \\
\hline \multirow{2}{*}{1} & \multirow{2}{*}{ Depending on the types of entities that act as insurance agents } & Individuals \\
\hline & & Legal entities \\
\hline \multirow{2}{*}{2} & \multirow{2}{*}{$\begin{array}{l}\text { Depending on the number of insurance companies whose } \\
\text { interests they represent }\end{array}$} & Corporate (dependent/single-mandate) \\
\hline & & Market (Independent/Multi-Mandate) \\
\hline \multirow{2}{*}{3} & \multirow{2}{*}{$\begin{array}{l}\text { Depending on the organization of insurance agents at legal } \\
\text { entities }\end{array}$} & System insurance agents \\
\hline & & Insurance agencies \\
\hline \multirow{3}{*}{4} & \multirow{3}{*}{$\begin{array}{l}\text { Depending on the form of interaction of insurance companies } \\
\text { with insurance agents }\end{array}$} & Genuine insurance agents (Direct insurance agents) \\
\hline & & General Insurance Agents \\
\hline & & Subagents \\
\hline \multirow{4}{*}{5} & \multirow{4}{*}{$\begin{array}{l}\text { Depending on the specialization of insurance agents in certain } \\
\text { types of insurance }\end{array}$} & Health care insurance agents \\
\hline & & Motor insurance agents \\
\hline & & Fire insurance agents \\
\hline & & Etc. \\
\hline \multirow{3}{*}{6} & \multirow{3}{*}{ Depending on the general specialization of insurance agents } & Life insurance agents \\
\hline & & Non-life insurance agents \\
\hline & & Multi-agents \\
\hline
\end{tabular}

\subsection{Insurance companies as participants in the insurance services distribution process}

Insurance companies, as participants in the insurance services distribution process, play an important role in the insurance market, especially in the area of life insurance. For example, their share in the insurance services distribution in European countries is about 20\% (Figure 2).

It should be noted that the sale of insurance services via insurance companies takes place directly in the office of the insurance company, as well as remotely. At the same time, each channel has its advantages.

In particular, for insurance companies, the remote distribution of insurance services provides the following benefits:

- reduction of operating and time expenses for distribution and accounting of insurance products;

- geographical diversification of insurance products;

- reduction of paperwork;

- increasing the loyalty of existing clients and expanding the insurance company presence in the direct insurance market;

- remote customer service;

- competitive advantages in the market due to the possibility of researching the product range of the insurer-competitor;

- virtually unlimited set of special marketing tools for online sales, including sending messages via e-mail, banners, promotion through the site of the insurer or partner, advertising, SMS-mailing, mobile Internet.

Regarding the insurer, the attractiveness of remote distribution is in the following:

- opportunity to purchase a policy at any convenient time;

- simplicity and versatility of payment methods;

- saving time;

- instant calculation of the service cost;

- additional auxiliary services that are not typical for traditional sales (skype communication, calculation of the policy cost for various programs, etc.) and remotely, without registration of a large number of documents, performing various operations; 
- range of remote payment methods (namely via the Internet, partner banks, via payment terminals and via courier when delivering a policy);

- possibility of receiving a discount;

- the ability to constantly track the necessary information through the "personal account", which is a personalized section, access to which is opened after entering the name and password of the client;

- comparison of insurance products and choice of insurance program that optimally meets the needs;

- lack of psychological influence of the insurance intermediary.

Along with the above, distribution in the insurer's office has its disadvantages, including the presence of psychological pressure from employees and the inability to compare the main features of insurance services at several insurance companies. The disadvantages of remote distribution include the lack of individual approach to the consumer, the high likelihood of fraud by the seller of insurance services, etc.

\subsection{Bancassurance in the insurance services distribution}

Ancillary insurance intermediaries also play a significant role in the insurance services distribution - in the life insurance services distribution, in particular. Close attention, hence, should be paid to the role of banks and, accordingly, the development of bancassurance. Namely the latter is the key distribution channel for insurance services in European countries (Figure 3).

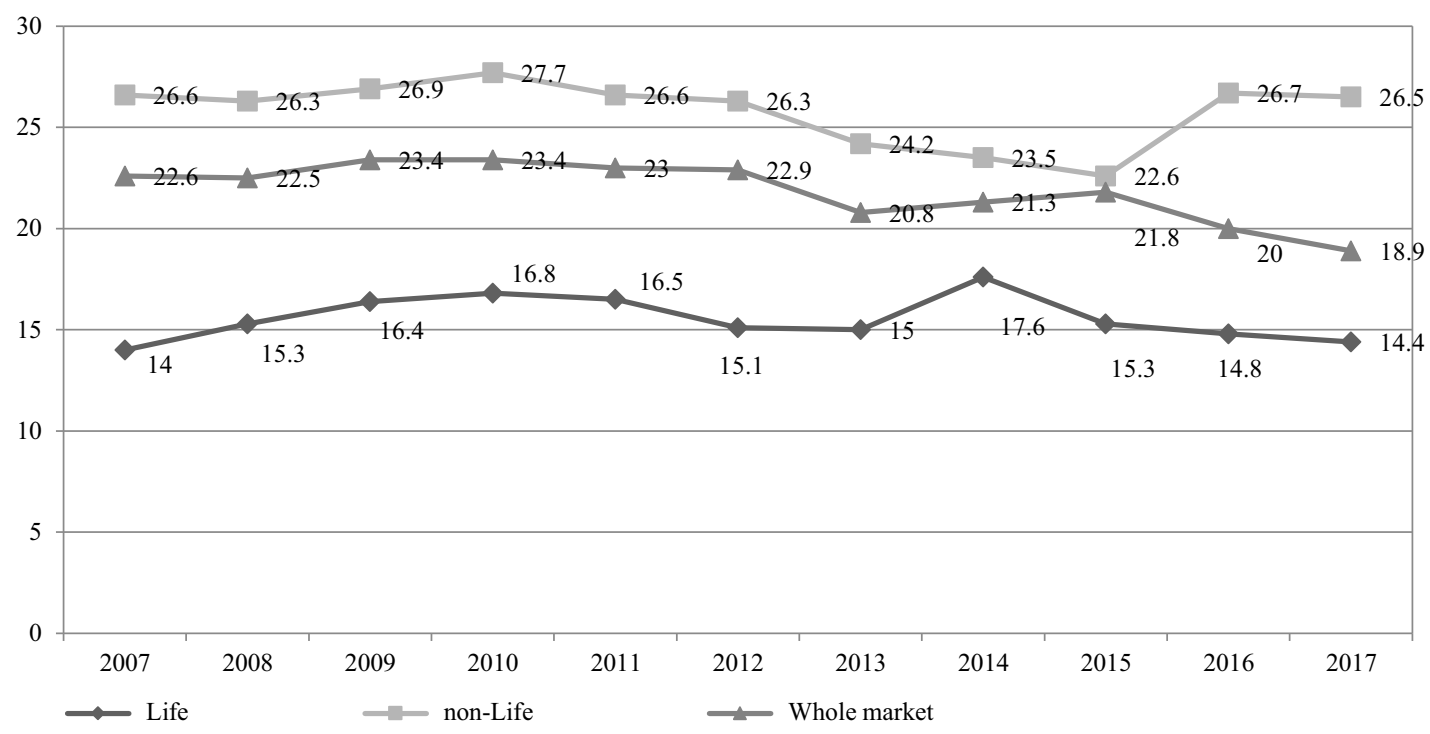

Figure 2. Share of insurance companies in the insurance services distribution in European countries in 2007-2017, \% (source: compiled by the authors according to Insurance Europe, 2020)

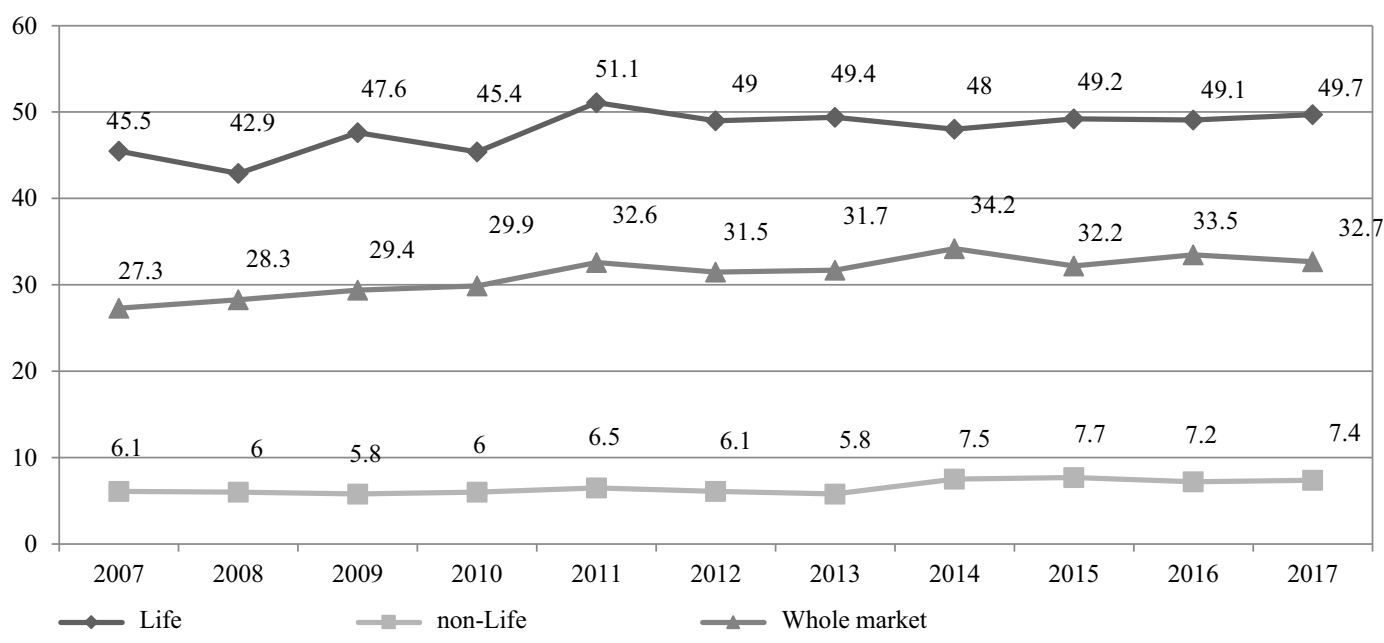

Figure 3. Share of bancassurance in the insurance services distribution in European countries in 2007-2017, \% (source: compiled by the authors using Insurance Europe, 2020) 
In general, the positive trends from the bancassurance introduction are represented in the following three aspects: financial (reduction of conventional and conditional variable costs), operating (simplification of technological processes, access to technologies and developments of the partner) and marketing (development of new products, increase in market share, geographical diversification).

\section{Innovations in the insurance services distribution}

Considering the peculiarities of the insurance services distribution, namely the process of their sale, it is especially important to pay attention to new channels of insurance distribution, where digitization is the key development driver. Hence, it is worth paying attention to the social networks acting as a link between the insurance company and the client and helping to establish a close connection between them. Insurance companies create their pages on social networks and use them as a platform for receiving complaints and for promoting new products or opportunities, and in some countries it is even possible buying the insurance products using social networks. Insurers, thanks to new capabilities, are able to track the consumer sentiment of potential insuring parties. As a result, insurance companies can tailor and personalize products to meet the specific needs of customers and their circumstances. However, despite the above mentioned, we should focus on the fact that the emergence of such "entities" that get familiar with the financial service, creates competition for insurers and acts for the latter as a threat. Thus, social media influences almost every aspect of the insurance industry, including the product development cycle, sales, and claims settlement. Proper communication in social networks helps building trust and establishing direct contact between insurance companies and their clients (Motashko, 2016).

Development of virtual insurance advisers in the insurance services distribution is another trend driven by digitization. The emergence of such feature enables consumers of insurance services obtaining the computer-generated advice on the type of insurance, insurance coverage, and special offer notices depending on the location of the consumer, etc.

Mobile applications are developing significantly in the insurance services distribution, due to the possibility of attracting new customers, the need to modernize customer service tools in order to increase their level of satisfaction, etc. (Ernst \& Young, 2014; Starostina et al., 2020).

Insurers provide a wide range of mobile features for the insurance market entities, namely:

- information search;

- purchase of insurance services;

- servicing the insurance policy;

- renewal of the insurance contract;

- opportunities at the occurrence of an insured event;

- maintenance of losses (Klapkiv, 2018).

We should also consider the price aggregators (comparison websites), which are becoming increasingly popular in the insurance distribution process, among the current trends in the insurance services distribution driven by digitization. Whereas previously policyholders traditionally needed personal interaction with insurance intermediaries, today they receive significant amounts of information via the Internet and directly compare insurance products and prices at the aggregator platforms (KPMG, 2017). According to some information, almost half of online insurance in Europe is sold through aggregators today (Keasler etal., 2018). Such an instrument of the insurance services distribution is used mainly by consumers for the purchase of insurance services in the field of home insurance and auto insurance, as well as in the field of tourist insurance. With the help of price aggregators, consumers of insurance services are given the opportunity to choose the best option for themselves, by comparing information from different insurance companies, before deciding to purchase an insurance service. However, the simplest form (basic model) of their operation implies that the comparison is mostly made on the basis of the price of the insurance service (covered risks sometimes), while offsetting other important features. The modern forms of price aggregators operating in advanced insurance markets are more complex and endowed with the functions of brokers and robot consultants.

\section{The distribution trends}

Thus, the key trends in the insurance services distribution in Europe, which will continue to be relevant in the future are the following:

- development of the new channels of insurance distribution, where digitization is the key driver;

- dominance of bancassurance in the insurance services distribution in the field of life insurance;

- development of multichannel distribution;

- predominance of agents and brokers in the distribution of non-standard insurance products;

- gradual reduction of the insurance intermediaries with the new opportunities provided by technological advances. 


\section{Distribution model of the future}

A study of the distribution channels for the insurance services in European countries showed that their structure is diverse, while the emphasis towards a particular distribution channelis changing. However, the new challenges, including those posed by the Covid-19 pandemic and digital power, necessitate a reformatting of existing approaches to the insurance servicesdistribution. At the same time, the model of adaptation of the insurance services distribution system to the new challenges should take into account various factors of influence, both exogenous and endogenous, which will become the driving forces in its development (Figure 4).

Exogenous factors of influence caused by the external environment of insurance distribution include:

- touch economy;

- digital power;

- virtualization;

- digital informatization;

- shocks of different nature (social, political, economic, natural);

- pandemics (including Covid 19).

The endogenous factors are the following:

- growing fast-changing customer requests;

- competition from "new players" in the market (trading platforms, technology giants GAFAA (Google, Apple, Facebook, Amazon and Alibaba));

- physical distancing;

- actualization of online sales;

- customer preferences in self-service;

- remote work of employees;

- reduction of customer loyalty.

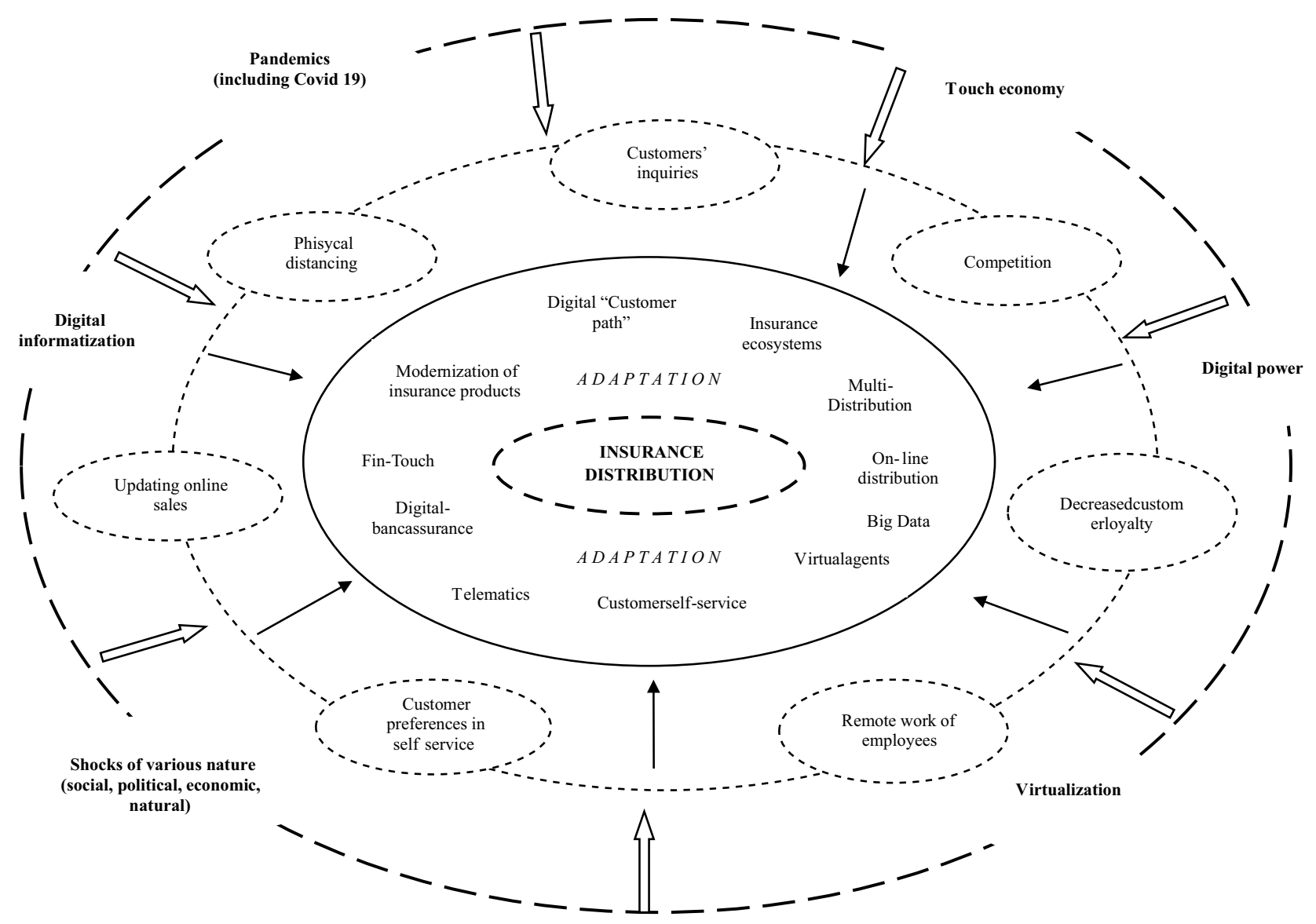

Figure 4. Model of adaptation of the insurance distribution system to the new challenges (source: developed by the authors) 
The distribution model of the future should include:

- improvement of the distribution channels via digitalization (virtual agents, telematics, P2P, compression Websites, etc.);

- expansion of partner channels (banking insurance, with fintech companies, with electronic trading platforms);

- development of insurance ecosystems;

- modernization of insurance products to online sales;

- introduction of a closed remote "client path";

- focus on Big Data;

- introduction of Multi-Channel Distribution;

- development of customer self-service points.

\section{Conclusions}

The paper proves that only those insurers paying due attention to the insurance services distribution will be able to remain competitiveunderthe new challenges.

As the study established, the concept of insurance services distribution can be considered in a narrow and broad senses. At the same time, its broad sense defines the essence of the insurance services distribution in a much better way, including not only the sale but also the range of additional activities in its concept. As determined, the search for the client and the sale are the main parts in the process of the insurance services distribution, where insurance companies, insurance intermediaries (agents and brokers), as well as alternative intermediaries (companies providing insurance services as a supplement to the products and services they offer) are the key participants.

The analysis of each of these entities' participation in the insurance services distribution during a ten-year period of 2007-2018 in the European countries and in Ukraine is performed.

The role of insurance intermediaries, namely insurance agents and brokers, in the implementation of insurance services is outlined. The types of insurance agents are systematized. The features and issues in the field of insurance mediation in Ukraine are identified. The advantages and disadvantages of traditional and remote insurance services distribution are considered, both from the position of the insurer and the insuring party. The role of bancassurance in the insurance services distribution in European countries is clarified.

Particular attention is paid to considering the trends and prospects for the use of innovations in the insurance services distribution, where digitalization is the key development driver. From this perspective, active communication in social networks, development of the use of virtual insurance advisers, modernization of customer service tools, including via mobile applications, and the spread of price aggregators are identified as the important trends.

As the research proves, the main trends in the field of insurance services distribution in European countries are the following: development of new channels of insurance distribution; dominance of bancassurance in the insurance services distribution in the area of life insurance; development of multichannel distribution; predominance of agents and brokers in the distribution of non-standard insurance services; the gradual diminution of the insurance intermediaries' role due to the new possibilities supported by technological advancements.

The model of adaptation of the insurance services distribution system to the new challenges is developed, which should take into account various influencing factors, both exogenous and endogenous. It is established that the Distribution model of the future should include: improvement of the distribution channels via digitalization; expansion of partner channels; development of insurance ecosystems; modernization of insurance products to online sales; introduction of a closed remote "client path"; focus on Big Data; introduction of Multi-channel Distribution and development of customer self-service points.

\section{Disclosure statement}

We declare that we do not have any competing financial, professional, o personal interests from other parties.

\section{References}

Bieck, C., \& Cornelius, A. (2014). Winning strategies for insurers. How industry leaders are excelling outside the comfort zone. IBM Institute for Business Value. https://www.ibm.com/downloads/cas/BWXDNV7Y

Bipar. (n.d.). Intermediaries. https://www.bipar.eu/en/intermediaries

Clipici, E., \& Bolovan, C. (2012). Bancassurance - Main insurance distribution and sale channel in Europe. Scientific Bulletin Economic Sciences, 11(1), 54-62. http://economic.upit.ro/repec/pdf/2012_3_7.pdf

Ernst \& Young (2014). Mobile technology in insurance. https://www.ey.com/Publication/vwLUAssets/EY-mobile-technology-in-insurance/\$FILE/EY-mobile-technology-in-insurance.pdf

European Commission. (n.d.). EU rules on insurance distribution. https://ec.europa.eu/info/business-economy-euro/banking-and-finance/insurance-and-pensions/insurance-distribution_en 
European Parliament \& Council of the European Union. (2016). Directive (EU) 2016/97 of the European Parliament and of the Council of 20 January 2016 on insurance distribution (recast). http://data.europa.eu/eli/dir/2016/97/oj

Insurance Europe. (2020). Annual Report 2019-2020. https://www.insuranceeurope.eu/2019-2020-annual-report-published

Keasler, S., Lorenz, J.-T., \& Schollmeier, F. (2018). Friends or foes: The rise of European aggregators and their impact on traditional insurers. McKinsey \& Company. https:/www.mckinsey.com/industries/financial-services/our-insights/friends-or-foesthe-rise-of-european-aggregators-and-their-impact-on-traditional-insurers

Klapkiv, Y. M. (2018). Mobile applications in the online distribution of insurance services. Scientific Journal of the Black Sea Petro Mohyla National University, Economics, 302(290), 42-47.

Klapkiv, Y., Klapkiv, L., \& Zarudna, N. (2018). Online distribution of insurance of civil liability of owners of vehicles, the experience of Poland, opportunities of Ukraine. Baltic Journal of Economic Studies, 4(1), 195-201. https://doi.org/10.30525/2256-0742/2018-4-1-195-201

KPMG. (2017). Clarityon insurance digitalization achieving agility: Towards a new business model. https://assets.kpmg/content/ $\mathrm{dam} / \mathrm{kpmg} / \mathrm{ch} / \mathrm{pdf} /$ clarity-on-insurance-digitalization-en.pdf

Motashko, T. P. (2016). World insurance market development under digitization. Bulletin of Taras Shevchenko National University of Kyiv. Economics, 182, 18-24. https://doi.org/10.17721/1728-2667.2016/182-5/3

OECD. (2020). Regulatory and supervisory framework for insurance intermediation. www.oecd.org/finance/insurance/Regulatory-and-Supervisory-Framework-for-Insurance-Intermediation.pdf

Pikus, R. V., \& Zakolodyazhnyi, V. O. (2016). Innovative distributionchannels in personal insurance. Investment: Practice and Experience, 7, 71-75. http://nbuv.gov.ua/UJRN/ipd_2016_7_13

Prykaziuk, N. V. (2017). Insurance system of Ukraine: Theory, methodology, practice: monograph. Logos.

Regan, L., \& Tennyson, Sh. (1998). Insurance distribution systems. In G. Dionne (Ed.), Huebner international series on risk, insurance, and economic security: Vol. 22. Handbook of insurance (pp. 709-748). Springer. https://doi.org/10.1007/978-94-010-0642-2_22

Sholoyko, A. S. (2016). Regulation of insurance mediation in conditions Euro integration processes of Ukraine. Bulletin of Taras Shevchenko National University of Kyiv. Economics, 180(3), 32-37. https://doi.org/10.17721/1728-2667.2016/180-3/5

Starostina, A., Pikus, R., \& Kravchenko, V. (2020). Innovative activities within Ukrainian insurance companies. Marketing and Management of Innovations, 2, 44-55. https://doi.org/10.21272/mmi.2020.2-03

Swiss Re. (2014). Digital distribution in insurance: A quiet revolution. Sigma, No 2. https://media.swissre.com/documents/sigma2_2014_en.pdf

Tkachenko, N., \& Riabokon, N. (2016). Systemic approach to sales of insurance products. Collection of scientific works of Cherkasy State Technological University. Series: Economic Sciences, 1(36). http://ven.chdtu.edu.ua/issue/view/5109 